\title{
Time allocation to active domains, physical activity, and health indicators in older adults: cross-sectional results from the OUTDOOR ACTIVE study
}

Imke Stalling ${ }^{*}(\mathbb{D}$, Birte Marie Albrecht, Friederike Doerwald and Karin Bammann

\begin{abstract}
Background: Physical activity (PA) is one of the key determinants of healthy ageing. Research showed that time allocation plays an important role in PA. Therefore, an understanding of the time use of older adults is crucial for developing PA programs. The aim of this study was to examine the associations of time allocation and objectively measured PA, and several health indicators in older adults.

Methods: In this cross-sectional study all 915 participants of the OUTDOOR ACTIVE study were included. The participants were 65 to 75 years old and resided in a subdistrict of Bremen, Germany (50.9\% female). The active domains were derived from the SLOTH model (leisure activities, occupation, active transport, home-based activities). PA was objectively measured with accelerometers over seven consecutive days. Binary logistic regressions were used to test the associations of total PA and time spent in the domains with several health indicators (self-rated health, overweight, obesity, activities of daily living (ADL)).
\end{abstract}

Results: Participants over the age of 70 years were significantly less physically active than those under 70 years and women were significantly more physically active than men. Regardless of age and sex, most time was spent on home-based activities (women: $118.5 \pm 87.8 \mathrm{~min} /$ day; men: $80.2 \pm 69.4 \mathrm{~min} /$ day). Both PA and time spent on leisure activities were associated with a lower risk of bad self-rated health $(0.36 ; 95 \%-C L: 0.20,0.65$ for PA; $0.93 ; 95 \%-C L$ : 0.87, 0.99 for leisure activities) and less limitations in ADL. PA and active transport seemed to lower the risk of overweight (0.39; 95\%-CL: 0.25, 0.62 for $\mathrm{PA} ; 0.80 ; 95 \%-\mathrm{CL}: 0.69,0.93$ for active transport) and obesity $(0.36$; 95\%-CL: 0.21, 0.60 for PA; $0.77 ;$ 95\%-CL: 0.64, 0.92 for active transport). Having an occupation was associated with a lower risk of bad self-rated health $(0.60 ; 95 \%-C L: 0.40,0.92)$.

Conclusions: The results of this study provide insights in the time allocation to active domains and total PA of older adults, as well as the associations with health indicators. These findings have important implications for the development of PA programs and guidelines. Future research should examine the associations further in longitudinal studies.

Keywords: Time use, Physical activity, Older adults, SLOTH model, Accelerometer

\footnotetext{
* Correspondence: stalling@uni-bremen.de

Institute for Public Health and Nursing Sciences (IPP), University of Bremen,

Grazer Straße 2a, 28359 Bremen, Germany
}

C C The Author(s). 2020 Open Access This article is licensed under a Creative Commons Attribution 4.0 International License, which permits use, sharing, adaptation, distribution and reproduction in any medium or format, as long as you give appropriate credit to the original author(s) and the source, provide a link to the Creative Commons licence, and indicate if changes were made. The images or other third party material in this article are included in the article's Creative Commons licence, unless indicated otherwise in a credit line to the material. If material is not included in the article's Creative Commons licence and your intended use is not permitted by statutory regulation or exceeds the permitted use, you will need to obtain permission directly from the copyright holder. To view a copy of this licence, visit http://creativecommons.org/licenses/by/4.0/ The Creative Commons Public Domain Dedication waiver (http://creativecommons.org/publicdomain/zero/1.0/) applies to the data made available in this article, unless otherwise stated in a credit line to the data. 


\section{Background}

One of the key determinants of healthy ageing is regular physical activity [1]. It is not only positively associated with increased quality of life and independent living, but also with decreased risks of numerous non-communicable diseases [2-4]. The World Health Organization recommends at least 150 min of moderate physical activity (PA) per week for adults, including leisure-time activities, active transportation, household chores, and occupational PA [2]. However, the prevalence of people meeting this recommendation declines with age [3]. In Germany, only $18.0 \%$ of the 60 - to 69 -year-olds and only $13.6 \%$ of the 70 to 79 -year-olds are physically active for at least $150 \mathrm{~min}$ per week [5]. Accelerometers have become the preferred method of measuring total PA [6-8]. A different approach is to assess time allocation, which helps identifying daily routines and thus might be easier to translate into PA recommendations than focusing on total PA. Previous studies have associated time spent on health-related behaviours with various health indicators, including PA [9, 10]. Research suggest that time spent on leisure, home-based, occupational, and transport-related PA are associated with self-rated health and body mass index (BMI) [11].Only few time use studies investigating associations with health indicators have focused on older adults $[9,12,13]$ and have rarely examined age differences within the group of older adults. Leisure time PA has several beneficial effects on health of older adults. A meta-analysis showed leisure time PA having the most benefits for mental health when compared to total PA and PA in other life domains [14]. Furthermore, it lowers the risk for all-cause, cardiovascular disease-related, and cancer-related mortality, even in older adults, who did not increase leisure time PA until late adulthood [15]. Higher levels of leisure time PA earlier in life are positively associated with better physical functioning in older age [16]. Being physically active at work has positive effects on health $[11,17,18]$, however these associations are not sufficiently researched for older adults. Most research on this age group includes the effects of retirement rather than occupation and the results regarding health are contrasting, as the review by van der Heide et al. showed [19]. A similar research situation exists in regards to transport-related PA. Active transport was found to be positively associated with better self-rated health, a lower risk for obesity as well as more overall healthy behaviours for adults [11, 20], not specifically older adults. Research on the associations of home-based activities and health indicators for this age group show inconsistent results, especially regarding self-reported health and overweight $[12,21,22]$. After retirement, the time that was previously spent at work needs to be newly allocated. Research showed that, compared to working adults, older retired people dedicate more of their time to household chores, passive as well as active leisure activities, and sleep.
However, PA through leisure activities remains the domain the least time is spent on each day, pre- and postretirement $[23,24]$. This could be due to increasing sedentary time and passive leisure activities, such as watching TV, with higher age [25], which might go at the expense of time spent on active leisure time. One study by Espinel et al. [26] distinguished time allocated to self-reported sedentary, light, and moderate to vigorous PA (MVPA) in non-working adults over 65 years. The reported activities were categorised into the different PA-levels using METs. Most of time spent in MVPA was caused by household chores, with women devoting more time to them than men. Men spent more time doing leisure activities. Only $25.0 \%$ of participants met sufficient MVPA-levels through leisure activities. The study did not find any associations with age or the socioeconomic status [26]. Eibich [27], contrastingly, found that time spent on leisure activities, active and inactive, increases by $1 \mathrm{~h}$ per day after retirement. He also found that time spent on repairs and gardening, as well as household chores increases and concludes that most retirees invest their new found time in an active lifestyle [27]. Taking together the literature, the existing evidence suggests that most older adults invest more time into household chores as well as leisure activities and has indicated some gender differences. However, past studies on time use of older adults have often assessed PA with self-report measures. Moreover, apart from gender, little is known about how other demographic variables might affect time use. One important variable in this context might be occupational status past retirement age. Past research has shown that retirees may have more leisure time than those still working, and might invest that time in health promoting behaviours, such as physical activity [28]. In addition, there might be age differences within the group of older adults regarding time use, though this has been insufficiently studied.

Since research on time allocation and its relation with health indicators regarding older adults is scarce, the aim of this cross-sectional study is to examine the associations between time spent in active life domains, objectively measured PA, and health indicators in older adults in Germany. Specifically, we focus on the differences between two age groups (under and over 70 years) and sex. We furthermore explore differences in time allocation between working and nonworking older adults. In this context, active domains comprise active leisure activities (e.g. sports, recreational walking, playing with children), occupation, active transport via bike or on foot and home-based activities (e.g. household chores, gardening).

Knowledge about time allocation of older adults to active domains and their associations with health indicators provides important background information for the development of future PA programs and guidelines. 


\section{Methods}

\section{Study design and population}

The OUTDOOR ACTIVE study is part of the regional prevention network AEQUIPA (Physical activity and health equity: primary prevention for healthy ageing) [29]. Research goals of OUTDOOR ACTIVE are to assess prevalence of PA in older adults, explore barriers and drivers for being physically active, and to develop and implement a community-based outdoor PA promotion program [30]. First baseline data were collected between October 2015 and August 2016 using 1) a selfadministered paper-pencil questionnaire regarding intrapersonal, interpersonal, and environmental determinants of PA, 2) a short physical examination (anthropometry and blood pressure) followed by a fitness test (modified public domain Senior Fitness Test [31] and handgrip strength test), and 3) accelerometry to objectively measure PA over the course of seven consecutive days. Eligibility criteria included being between 65 and 75 years old, being non-institutionalised, and living in the district Hemelingen in the city of Bremen, in the North-West of Germany. Address data were provided by the registry office in Bremen in August 2015. All eligible individuals initially received a letter and were later contacted by phone, in cases where the number could be obtained through one of the available registers. In total, 4304 individuals were registered in the study region. Of these, 615 people were excluded because of acute health problems $(n=242)$, language barriers $(n=22)$, moving out of the study region $(n=295)$, or death $(n=56)$. Out of the remaining eligible 3689 individuals, 720 were never reached, 2052 refused participation, and 915 individuals took part in the OUTDOOR ACTIVE study (response rate: $24.8 \%$ ). All participants provided written informed consent and the study was approved by the ethics committee of the University of Bremen in September 2015. In the present study, all 915 OUTDOOR ACTIVE participants were included. For analyses with accelerometer data, 570 participants, who wore the accelerometer for at least $20 \mathrm{~h}$ a day, were included. The subjective and objective PA measurements do not assess the same kind of PA and should not be used interchangeably. We decided to use both because they can complement each other and offer a richness of information [32, 33]. Therefore, we can analyse the associations of health indicators with domain-specific PA as well as objective total PA, and get broader insights into the topic.

\section{Measures}

\section{Accelerometer-assessed physical activity}

To measure PA objectively, ActiGraph GT3x-BTw accelerometers were handed to the participants following the fitness test. They were asked to wear them on seven consecutive days, ideally for $24 \mathrm{~h}$ straight, on their non- dominant wrist. The epoch length was set to $30 \mathrm{~Hz}$. The participants were given short instructions on when to take them off (e.g. when using the sauna) and how to put them back on. Members of the project group collected the accelerometers after 1 week at the participants' homes, cleaned them, and downloaded the data with ActiLife (Version 6.13.3 ActiGraph LLC, Pensacola, FL, USA). After preparing the data in ActiLife for statistical analyses, it was then transferred to the SPSS database. Average daily counts per minute (vector magnitudes) were included in the analyses as a continuous variable. PA was not further classified, because of the lack of established cut-offs for older adults [34] and to avoid loss of information [35]. Non-wear time was defined as 90 consecutive minutes with zero counts [36].

\section{Assessment of the SLOTH model domains}

We employed the time budget SLOTH model, which groups the time spent into the five domains sleep, leisure, occupation, transport, and home-based activities [37]. For this study, we only investigated active activities (see Table 1). Active activities and time spent in these domains were assessed by self-administered questionnaire that was part of the baseline survey. The questions referred to current activities but included no specific time frame. Sleep was considered a passive activity and was therefore not included in the analyses.

For assessment of active leisure, we asked participants to report all currently performed organised (e.g. sports club, sports group, or a gym) as well as non-organised activities. The reported hours per week for the individual activities were added up, excluding riding a bike, since this activity could also be interpreted as a mode of transport. All paid and unpaid work including volunteer work was included in the occupation domain. Time spent on carrying out the occupation was not asked and could

Table 1 SLOTH domains and their passive and active activities

\begin{tabular}{|c|c|c|}
\hline Domains & Type & Activities \\
\hline \multirow[t]{2}{*}{ Sleep } & Passive & Sleep \\
\hline & Active & - \\
\hline \multirow[t]{2}{*}{ Leisure } & Passive & Watching TV, reading etc. \\
\hline & Active & $\begin{array}{l}\text { Sports, active recreational activities, } \\
\text { playing with children etc. }\end{array}$ \\
\hline \multirow[t]{2}{*}{ Occupation } & Passive & - \\
\hline & Active & $\begin{array}{l}\text { All paid and unpaid work including } \\
\text { volunteer work }\end{array}$ \\
\hline \multirow[t]{2}{*}{ Transport } & Passive & Public transport, car, motor bike etc. \\
\hline & Active & Cycling, walking \\
\hline \multirow[t]{2}{*}{ Home-based } & Passive & - \\
\hline & Active & $\begin{array}{l}\text { Household chores, gardening, repairs } \\
\text { around the house }\end{array}$ \\
\hline
\end{tabular}


therefore not be included in the analyses. Time spent in active transport was assessed with a question based on the public domain Neighbourhood Environment and Walkability Scale (NEWS) [38] using 12 common destinations. The usual mode of transport as well as the minutes spent on the trips were assessed. To calculate the average daily time spent in active transport, the frequency for each destination was estimated (see additional file 1). For the analyses only transport via bike and on foot were used. Home-based activities, which comprise housework and gardening, were assessed with the same question as leisure activities (i.e., hours per week engaging in the activities). To reduce the number of outliers, the maximum possible time for housework and gardening was set to $40 \mathrm{~h}$ per week and for the rest of the active SLOTH dimensions to $20 \mathrm{~h}$ per week.

\section{Assessment of health indicators}

Self-rated health and activities of daily living (ADL) were assessed via questions from the public domain SF-36 v1.0 questionnaire [39, 40]. BMI was calculated using body weight (in $\mathrm{kg}$ ) and height (in $\mathrm{m}$ ), both measured during the short physical examination with a Kern MPC $250 \mathrm{~K} 100 \mathrm{M}$ personal floor scale (Kern \& Sohn GmbH, Ballingen, Germany) and a Seca 217 mobile Stadiometer (Seca GmbH \& Co. KG, Hamburg, Germany), respectively. The classification by the WHO [41] was used for the distinction between normal weight, overweight, and obesity.

\section{Sociodemographic information}

Participant's age, sex, marital status, educational status, net household income, and occupational status were assessed by a self-administered questionnaire. To assign each participant a socio-economic status (SES), an additive social class index was calculated using educational years (school years and training years combined), net household income (OECD), and the Standard International Occupational Prestige Scale based on Helmert et al. [42]. Missing values were imputed using multiple imputation in SPSS 22 (IBM Corp. Armonk, NY) with five imputations, and the mean value as the final data. The SES was categorized into quintiles.

\section{Statistical analyses}

For the descriptive analyses absolute and relative frequencies were calculated for education level, marital status, socio-economic status, self-reported health, and occupational status. Means and standard deviations were calculated for age, total PA (Counts per minute, from here on $\mathrm{CPM}$ ), and time spent in the active dimensions of the SLOTH model per day in minutes. The descriptive analyses were done separately for men and women, as well as for the two age groups (under and over 70 years). Each result is shown for the total study sample and separately for those participants, who actually perform these activities. Furthermore, the percentage of people engaging in these activities is shown. To test for significant differences between groups, Mann-WhitneyU-tests were conducted since none of the variables were normally distributed. Binary logistic regressions were used to test if total PA and the time spent in the active SLOTH model domains are significantly associated with several health outcomes (self-rated health, overweight, obesity, ADL). For analyses including objective PA data only participants, who wore the accelerometer for at least $20 \mathrm{~h}$ on average per day, were taken into account. All statistical analyses were conducted with SPSS 22.0 (IBM Corp. Armonk, NY).

\section{Results}

Table 2 shows descriptive characteristics of the study population. $50.9 \%$ of the participants were female and the mean age was $69.9 \pm 3.1$ years. $82.1 \%$ of the participants had lower secondary education, $59.8 \%$ belonged to middle class. $58.0 \%$ of the female and $82.2 \%$ of the male participants were married, and about half of them had a paid occupation or did volunteer work. The majority of participants (78.8\%) rated their health as at least good with decreasing percentage in higher age groups. The mean daily total PA shows a difference between men and women and a decline with higher age. Women over the age of 70 years were overall significantly less physically active than those younger than 70 years $(1700.4 \pm$ 432.4 $\mathrm{CPM}$ vs. $1840.0 \pm 466.7 \mathrm{CPM}, \mathrm{z}=-2.6, p=<.01)$. The difference in men was also statistically significant, with older men being less physically active than their younger counterparts $(1366.5 \pm 316.2 \mathrm{CPM}$ vs. $1475.1 \pm$ $352.8 \mathrm{CPM}, \mathrm{z}=-2.9, p=<.01)$. Women were significantly more physically active than men $(1770.4 \pm 454.6$ CPM vs. $1426.1 \pm 340.5$ CPM, $\mathrm{z}=-9.4, p=<.001)$.

Table 3 reports the average time spent in the active domains of the SLOTH model stratified by age and sex in minutes per day. Disregarding occupation, where no time data is available, most time is spent on home-based activities (women: $118.5 \pm 87.8 \mathrm{~min} /$ day; men: $80.2 \pm 69.4 \mathrm{~min} /$ day), followed by active leisure time (women: $35.9 \pm 34.0$ $\mathrm{min} /$ day; men: $41.9 \pm 36.8 \mathrm{~min} /$ day), and time in active transport (women: $14.4 \pm 8.5 \mathrm{~min} /$ day; men: $12.5 \pm 9.4$ $\mathrm{min} /$ day). This pattern is consistent in all gender and age groups. The largest difference by age was found for homebased activities in women, where women $\geq 70$ years spent roughly $20 \mathrm{~min}$ more time than younger women. There were sex differences in the amount of time spent in the investigated domains. Men spent statistically significantly more time on leisure activities than women $(41.9 \pm 36.8$ vs. $35.9 \pm 34.0 \mathrm{~min} /$ day, $\mathrm{z}=-2.3, p=.02$ ). Women allocated statistically significantly more time to active 
Table $\mathbf{2}$ Characteristics of the study population

\begin{tabular}{|c|c|c|c|c|c|c|}
\hline & \multicolumn{3}{|l|}{ Women } & \multicolumn{3}{|l|}{ Men } \\
\hline & $\begin{array}{l}\text { Total } \\
(n=465)\end{array}$ & $\begin{array}{l}<70 \text { yrs. } \\
(n=210)\end{array}$ & $\begin{array}{l}\geq 70 \text { yrs. } \\
(n=255)\end{array}$ & $\begin{array}{l}\text { Total } \\
(n=448)\end{array}$ & $\begin{array}{l}<70 \text { yrs. } \\
(n=227)\end{array}$ & $\begin{array}{l}\geq 70 \text { yrs. } \\
(n=221)\end{array}$ \\
\hline & \multicolumn{3}{|l|}{ n (\%) } & \multicolumn{3}{|l|}{ n (\%) } \\
\hline \multicolumn{7}{|l|}{ Education } \\
\hline Lower secondary education & $374(85.0)$ & $162(81.8)$ & $210(87.6)$ & $332(79.0)$ & $151(70.5)$ & $181(87.9)$ \\
\hline Upper secondary education & $56(12.7)$ & $31(15.7)$ & $25(10.4)$ & 77 (18.3) & $56(26.2)$ & $21(10.2)$ \\
\hline No degree & $10(2.2)$ & $5(2.5)$ & $5(2.1)$ & $11(2.6)$ & $7(3.2)$ & $4(2.0)$ \\
\hline \multicolumn{7}{|l|}{ Socioeconomic status } \\
\hline Lower class & $108(24.6)$ & $43(21.9)$ & $64(26.6)$ & $67(15.9)$ & $32(15.0)$ & $35(16.9)$ \\
\hline Middle class & $264(60.1)$ & $112(57.1)$ & $151(62.7)$ & $250(59.4)$ & $122(57.0)$ & $128(61.8)$ \\
\hline Upper class & $67(15.3)$ & $41(20.9)$ & $26(10.8)$ & $104(24.7)$ & $60(28.0)$ & $44(21.3)$ \\
\hline \multicolumn{7}{|l|}{ Marital status } \\
\hline Married & $251(58.0)$ & $118(59.9)$ & $133(56.4)$ & $347(82.2)$ & $179(83.3)$ & $168(81.2)$ \\
\hline Divorced & $63(14.5)$ & $35(17.8)$ & $28(11.9)$ & $35(8.3)$ & $19(8.8)$ & $16(7.7)$ \\
\hline Widowed & $99(22.9)$ & $33(16.8)$ & $66(28.0)$ & $20(4.7)$ & $4(1.9)$ & $16(7.7)$ \\
\hline Unwed/single & $20(4.6)$ & $11(5.6)$ & $9(3.8)$ & $20(4.7)$ & $13(6.0)$ & $7(3.4)$ \\
\hline \multicolumn{7}{|l|}{ Occupational status } \\
\hline Volunteer work only & $162(38.3)$ & $76(40.0)$ & $86(38.4)$ & $114(28.6)$ & $58(28.0)$ & $56(29.3)$ \\
\hline Paid occupation only & $37(8.8)$ & $26(13.7)$ & $11(4.9)$ & $67(16.8)$ & $42(20.3)$ & $25(13.1)$ \\
\hline Paid occupation + volunteer work & $14(3.3)$ & $11(5.8)$ & $3(1.3)$ & $18(4.5)$ & $10(4.8)$ & $8(4.2)$ \\
\hline No occupation & $201(47.5)$ & $77(40.5)$ & $124(55.4)$ & $199(50.0)$ & $97(46.9)$ & $102(53.4)$ \\
\hline \multicolumn{7}{|l|}{ Self-reported health status } \\
\hline Less good or bad & $103(23.6)$ & $39(19.8)$ & $64(27.0)$ & 78 (18.6) & $37(17.1)$ & $41(20.1)$ \\
\hline Good & $258(59.2)$ & $117(59.4)$ & $139(58.6)$ & $244(58.1)$ & $126(58.3)$ & $118(57.8)$ \\
\hline \multirow[t]{2}{*}{ Very good or excellent } & $75(17.2)$ & $41(20.9)$ & $34(14.4)$ & $98(23.4)$ & $53(24.6)$ & $45(22.0)$ \\
\hline & \multicolumn{3}{|l|}{ Mean (SD) } & \multicolumn{3}{|l|}{ Mean (SD) } \\
\hline Age (years) & $70.0(3.1)$ & $67.0(1.4)$ & $72.43(1.7)$ & $69.8(3.1)$ & $67.2(1.5)$ & $72.5(1.9)$ \\
\hline Total PA (CPM) & $1770.4(454.6)$ & $1840.0(466.7)$ & $1700.4(432.4)$ & $1426.1(340.5)$ & $1475.1(352.8)$ & $1366.5(316.2)$ \\
\hline
\end{tabular}

transport $(14.4 \pm 8.5$ vs. $12.5 \pm 9.4 \mathrm{~min} /$ day, $\mathrm{z}=-3.8, p=$ $<.01)$, home-based activities (118.5 \pm 87.8 vs. $80.2 \pm 69.4$ $\mathrm{min} /$ day, $\mathrm{z}=-7.1, p=<.001$ ), and housework (91.2 \pm 69.5 vs. $44.1 \pm 37.5 \mathrm{~min} /$ day, $\mathrm{z}=-11.4, p=<.001)$ per day.

Table 4 shows the average time spent in the active SLOTH domains stratified by occupation status and sex. Regardless of the occupation status and gender, most time is spent on home-based activities (women with no occupation: $118.3 \pm 89.3 \mathrm{~min} /$ day; with an occupation: $116.5 \pm 86.1$ $\mathrm{min} /$ day; men with no occupation: $83.2 \pm 68.3 \mathrm{~min} /$ day; with an occupation: $67.7 \pm 75.8 \mathrm{~min} /$ day). Participants with a paid occupation spent less time on each domain than those without an occupation. The only exception can be observed in women regarding housework, where employed women devoted more time to housework activities than unemployed women (101.5 $\pm 76.2 \mathrm{~min} /$ day vs. $90.0 \pm 69.2$ $\mathrm{min} /$ day). However, none of the differences by occupation status were statistically significant, regardless of sex.
Table 5 presents the results of the binary logistic regressions for the associations of health indicators with time allocation and total PA adjusted for age and sex. The results indicate that more time spent on leisure activities reduces the risk of bad self-rated health (OR: 0.93; 95\%-CL: $0.87,0.99)$ and limitations in activities of daily living, such as moderate activities (OR: 0.88; 95\%CL: 0.83, 0.94), bending, kneeling, and stooping (OR: 0.93; 95\%-CL: $0.89,0.97)$ as well as walking more than 1 km (OR: 0.90; 95\%-CL: 0.84, 0.96). Participants without an occupation were more likely to rate their health as not good (OR: 0.60; 95\%-CL: 0.40, 0.92) compared to those with a post-retirement occupation. More time spent in active transport seemed to lower the risk of having limitations when walking more than $1 \mathrm{~km}$ (OR: 0.79; 95\%-CL: 0.65, 0.96), being overweight (OR: 0.80; 95\%-CL: 0.69, 0.93), or obese (OR: 0.77; 95\%-CL: 0.64, 0.92). The results indicated that higher total PA 
Table 3 Time allocation to active SLOTH domains in minutes per day by age and sex

\begin{tabular}{|c|c|c|c|c|c|c|}
\hline & \multicolumn{3}{|l|}{ Women } & \multicolumn{3}{|l|}{ Men } \\
\hline & Total $(n=465)$ & $<70$ yrs. $(n=210)$ & $\geq 70$ yrs. $(n=255)$ & Total $(n=448)$ & $<70$ yrs. $(n=227)$ & $\geq 70$ yrs. $(n=221)$ \\
\hline & \multicolumn{3}{|l|}{ Mean (SD) } & \multicolumn{3}{|l|}{ Mean (SD) } \\
\hline \multicolumn{7}{|l|}{ Leisure, only active } \\
\hline Total & $21.1(31.4)$ & $22.8(29.4)$ & $19.6(33.0)$ & $20.9(33.4)$ & $24.6(36.8)$ & $17.2(29.2)$ \\
\hline Participation rate $\%$ & 58.7 & 62.9 & 55.3 & 50.0 & 55.9 & 43.9 \\
\hline Performers only & $35.9(34.0)$ & $36.2(29.8)$ & $35.5(37.5)$ & $41.9(36.8)$ & $43.9(39.6)$ & $39.2(32.9)$ \\
\hline \multicolumn{7}{|c|}{ Occupation, including volunteer work } \\
\hline Total & a & & & a & & \\
\hline Participation rate $\%$ & 56.8 & 63.3 & 51.4 & 55.6 & 57.3 & 53.9 \\
\hline Performers only & a & & & a & & \\
\hline \multicolumn{7}{|l|}{ Transport, only active } \\
\hline Total & $11.9(9.5)$ & $11.3(8.4)$ & $12.4(10.2)$ & $10.5(9.7)$ & $10.6(10.1)$ & $10.4(9.3)$ \\
\hline Participation rate \% & 84.6 & 85.7 & 80.8 & 83.9 & 86.3 & 81.5 \\
\hline Performers only & $14.4(8.5)$ & $13.2(7.6)$ & $15.4(9.1)$ & $12.5(9.4)$ & $12.2(9.9)$ & $12.7(8.8)$ \\
\hline \multicolumn{7}{|l|}{ Home-based activities } \\
\hline Total & $101.4(91.3)$ & $93.4(79.8)$ & $108.0(99.4)$ & $69.5(70.2)$ & $70.1(70.5)$ & $68.8(70.0)$ \\
\hline Participation rate \% & 85.6 & 86.7 & 84.7 & 86.6 & 88.1 & 85.1 \\
\hline Performers only & 118.5 (87.8) & $107.5(76.1)$ & $127.5(95.8)$ & $80.2(69.4)$ & $79.5(69.9)$ & $80.9(69.1)$ \\
\hline \multicolumn{7}{|l|}{ Housework } \\
\hline Total & $76.5(72.0)$ & $72.2(63.7)$ & $80.1(78.1)$ & $35.4(37.9)$ & $37.4(37.8)$ & $33.4(38.0)$ \\
\hline Participation rate \% & 83.9 & 85.7 & 82.4 & 80.4 & 82.8 & 77.8 \\
\hline Performers only & $91.2(69.5)$ & $84.2(60.9)$ & $97.2(75.7)$ & $44.1(37.5)$ & $45.1(37.1)$ & $42.9(38.1)$ \\
\hline \multicolumn{7}{|l|}{ Gardening } \\
\hline Total & $24.9(39.4)$ & $21.1(32.9)$ & $28.0(43.8)$ & $34.0(48.8)$ & $32.7(49.2)$ & $35.4(48.6)$ \\
\hline Participation rate \% & 62.2 & 61.4 & 62.8 & 72.3 & 70.0 & 74.7 \\
\hline Performers only & $40.0(43.4)$ & $34.4(36.2)$ & $44.6(48.1)$ & $47.1(51.8)$ & $46.7(52.9)$ & $47.4(50.9)$ \\
\hline
\end{tabular}

Data not available

SD Standard deviation

increases the likelihood for a better self-rated health (OR: 0.36; 95\%-CL: 0.20, 0.65) and decreases the risk of having limitations regarding moderate activities (OR: 0.55; 95\%-CL: 0.34, 0.89), as well as bending, kneeling, and stooping (OR: 0.38; 95\%-CL: 0.24, 0.60). The risk of being overweight (OR: 0.39 ; 95\%-CL: $0.25,0.62$ ) or obese (OR: 0.36; 95\%-CL: $0.21,0.60$ ) also decreased with increased total PA. Time spent in home-based activities did not seem to be associated with any of the health outcomes.

\section{Discussion}

This study investigated age and sex specific differences in time use in three active domains (leisure, transport, home-based) and examined associations between time allocation in these domains and objectively measured PA with different health outcomes (self-rated health, BMI, ADL). Furthermore, we explored differences in time allocation between working and non-working older adults. Results showed age and sex differences in total PA as well as in time use in the active domains. Participants with a paid occupation spent less time in almost every active domain than participants without an occupation. Furthermore, the results showed several associations between active domains and health indicators. While total PA was associated with all investigated health indicators, time spent in the different SLOTH domains showed a more distinctive pattern, with leisure activities and active transport being most influential. Time spent in active leisure time was associated with better selfrated health and having no limitations in ADL. Time spent on active transport was associated with having no limitations when walking more than 1 kilometer and being normal weight. Having an occupation was only associated with better self-rated health. Homebased activities showed no significant associations with any of the investigated health indicators. 
Table 4 Time allocation to active SLOTH domains in minutes per day by occupation status and sex

\begin{tabular}{|c|c|c|c|c|}
\hline & \multicolumn{2}{|l|}{ Women } & \multicolumn{2}{|l|}{ Men } \\
\hline & No occupation $(n=360)$ & Occupation $^{\mathrm{a}}(n=52)$ & No occupation ( $n=312)$ & Occupation $^{\mathrm{a}}(n=85)$ \\
\hline & \multicolumn{2}{|l|}{ Mean (SD) } & \multicolumn{2}{|l|}{ Mean (SD) } \\
\hline \multicolumn{5}{|l|}{ Leisure, only active } \\
\hline Total & $23.0(33.2)$ & $19.8(27.3)$ & $22.8(35.7)$ & $19.8(27.9)$ \\
\hline Participation rate \% & 61.4 & 67.3 & 52.6 & 56.5 \\
\hline Performers only & $37.4(35.4)$ & $29.4(28.8)$ & $43.3(39.2)$ & $35.0(29.0)$ \\
\hline \multicolumn{5}{|l|}{ Transport, only active } \\
\hline Total & $13.1(9.4)$ & $10.2(8.3)$ & $11.7(10.1)$ & $9.3(8.0)$ \\
\hline Participation rate \% & 89.7 & 78.9 & 91.0 & 87.1 \\
\hline Performers only & $14.6(8.7)$ & $12.9(7.3)$ & $12.9(9.9)$ & $10.7(7.7)$ \\
\hline \multicolumn{5}{|l|}{ Home-based activities } \\
\hline Total & $107.2(91.8)$ & $105.3(88.8)$ & $77.1(69.2)$ & $61.3(74.8)$ \\
\hline Participation rate \% & 90.6 & 90.4 & 92.6 & 90.6 \\
\hline Performers only & $118.3(89.3)$ & $116.5(86.1)$ & $83.2(68.3)$ & $67.7(75.8)$ \\
\hline \multicolumn{5}{|l|}{ Housework } \\
\hline Total & $80.3(71.1)$ & $87.9(78.9)$ & $39.7(38.8)$ & $31.8(37.1)$ \\
\hline Participation rate \% & 89.2 & 86.5 & 86.9 & 81.2 \\
\hline Performers only & $90.0(69.2)$ & $101.5(76.2)$ & $45.7(38.1)$ & $39.1(37.5)$ \\
\hline \multicolumn{5}{|l|}{ Gardening } \\
\hline Total & $26.9(40.7)$ & $17.5(21.7)$ & $37.4(46.6)$ & $29.6(60.4)$ \\
\hline Participation rate $\%$ & 64.7 & 69.2 & 79.2 & 67.1 \\
\hline Performers only & $41.5(44.2)$ & $25.2(22.4)$ & $47.2(47.7)$ & 44.1 (69.4) \\
\hline
\end{tabular}

anly paid occupation

SD Standard deviation

Our results regarding total PA are in line with previous research. Total PA is linked to better self-rated health [43, 44], overweight and obesity [45], and physical functioning $[46,47]$. Our study showed a statically significant higher objectively measured PA in women compared to men. These results are in contrast to several other studies objectively measuring PA in older adults. The systematic review by Sun et al. [3], for instance, found older men to be more physically active than older women. These differences could arise from differences in PA measurements. In this study the accelerometer was worn on the non-dominant wrist, since it tends to have a higher compliance compared to hip placement [48]. However, most studies use PA monitors on the hip, which results in differences in the measured movements, especially regarding the upper body [3]. Since the

Table 5 Results of binary logistic regression on predicting health indicators, adjusted for age and sex

\begin{tabular}{|c|c|c|c|c|c|c|}
\hline & Bad self-rated health & $\begin{array}{l}\text { Limitations when } \\
\text { doing moderate } \\
\text { activities (ADL) }\end{array}$ & $\begin{array}{l}\text { Limitations when } \\
\text { bending, kneeling, } \\
\text { stooping (ADL) }\end{array}$ & $\begin{array}{l}\text { Limitations } \\
\text { when walking } \\
>1 \mathrm{~km} \text { (ADL) }\end{array}$ & Overweight & Obesity \\
\hline & OR (95\%-CL) & OR (95\%-CL) & OR (95\%-CL) & OR (95\%-CL) & OR (95\%-CL) & OR (95\%-CL) \\
\hline $\begin{array}{l}\text { Leisure, only active } \\
\text { (hrs/week) }\end{array}$ & $0.93(0.87,0.99)$ & $0.88(0.83,0.94)$ & $0.93(0.89,0.97)$ & $0.90(0.84,0.96)$ & $0.96(0.92,1.00)$ & $0.96(0.91,1.01)$ \\
\hline Occupation (yes/no) & $0.60(0.40,0.92)$ & $0.90(0.63,1.30)$ & $0.90(0.65,1.25)$ & $0.77(0.52,1.13)$ & $0.76(0.53,1.08)$ & $0.80(0.54,1.17)$ \\
\hline $\begin{array}{l}\text { Transport, only active } \\
\text { (hrs/week) }\end{array}$ & $0.96(0.79,1.16)$ & $1.07(0.91,1.25)$ & $0.94(0.81,1.09)$ & $0.79(0.65,0.96)$ & $0.80(0.69,0.93)$ & $0.77(0.64,0.92)$ \\
\hline $\begin{array}{l}\text { Home-based activities } \\
\text { (hrs/week) }\end{array}$ & $0.99(0.97,1.01)$ & $0.99(0.98,1.01)$ & $1.00(0.99,1.02)$ & $0.99(0.97,1.01)$ & $0.99(0.97,1.00)$ & $0.98(0.96,1.00)$ \\
\hline Total PA ${ }^{a}$ (CPM) & $0.36(0.20,0.65)$ & $0.55(0.34,0.89)$ & $0.38(0.24,0.60)$ & $0.61(0.36,1.02)$ & $0.39(0.25,0.62)$ & $0.36(0.21,0.60)$ \\
\hline
\end{tabular}

${ }^{a}$ Only participants with at least $20 \mathrm{~h}$ /day of accelerometer data included $(n=570)$

$A D L$ Activities of daily living, $C L$ Confidence limits, CPM Counts per minute, OR Odds ratio

Statistically significant results in bold 
women in our sample devote a lot of time to housework, which includes lots of upper body movements, it is possible that the higher amount of PA stems from this. Moreover, our study showed that participants older than 70 years were significantly less physically active than those under 70 years. Yet, they spent more time in several active SLOTH domains with increasing age. One reason could be the decreasing proportion of people having a paid occupation or doing volunteer work as they get older (women: $63.3 \%$ compared to $51.4 \%$, men: $57.3 \%$ compared to $53.9 \%$ ), which leads them to allocate their time differently. Another possibility is that with increasing age, more time might be required to perform certain tasks, because of the ageing-related decline in health [49]. Both men and women in the older age group (age 70+ years) more often reported less good or bad health than the younger ones. Since our data only provides information about the time allocation to active domains and cannot provide information about the intensity, we can only speculate that although the time spent in the SLOTH domains increases with higher age, the intensity might decrease. Spinney et al. [50], for example, found decreasing rates of older Canadians meeting PA recommendations with increasing age, when looking at the active domains.

In our study, women reported spending 35.9 and men $41.9 \mathrm{~min}$ per day in active leisure. In line with our results, a systematic review [24] reported average leisure time of 0.5 to $1 \mathrm{~h}$ per day, with men devoting more time to it than women. Krantz-Kent and Stewart [51] found similar results in their American study. Our findings further indicated that time spent in active leisure is associated with better self-rated health, which is supported by the studies by Abu-Omar and Rotten [11], as well as Kaleta and colleagues [52]. Both of these studies, however, did not focus on older adults specifically. Time doing leisure activities was also associated with lower risks of having limitations in ADL, which is in accordance with previous research $[16,53]$. The results emphasize the importance of active leisure for health.

Since we did not assess time spent on occupational $\mathrm{PA}$, we have compared the time spent in the remaining domains between employed and unemployed participants. The results indicated that women and men without an occupation spent more time in each domain than the participants with an occupation. The only exception is working women, who spent more time doing housework than their non-working counterparts. A study by Flood and Moen [54] also found that employment is negatively associated with time being physically active. Having an occupation was associated to better self-rated health in our study. Research on health effects of occupation in older adults is scarce, as often is the focus rather on the effects of retirement. A systematic review on retirement found contrasting results in the literature, with retirement having positive as well as adverse effects on health [19]. One possible explanation are diverging definitions of occupation and retirement, for example if doing unpaid volunteer work counts as having an occupation.

Our participants only spent a short time (Women: $14.4 \mathrm{~min} /$ day; Men: $12.5 \mathrm{~min} /$ day) in active transport. Sprod and colleagues $[23,55]$ reported almost three times more minutes per day being spent on active travel. These differences could be a result of us only using everyday destinations, whereas Sprod et al. included every destination. Another explanation could be the difference in infrastructure between the study countries (Australia vs. Germany), that leads to the participants having to cover longer routes. Time spent in active transport was associated with a lower risk of overweight and obesity. Additionally, it was associated with a lower risk of having limitations in walking more than $1 \mathrm{~km}$. In this context, limited mobility could be a barrier to PA and using active transport. We therefore performed a sensitivity analysis excluding participants who rely on mobility aids. The results do not change by much although they are statistically significant anymore (before: OR: $0.79,95 \%-C I: 0.65,0.96$; sensitivity analysis: OR: 0.86, 95\%-CI: 0.70, 1.05). Furthermore, possible reverse causation should be taken into account, since the data only stems from a cross-sectional study. A comparison with existing research is difficult, since other time use studies often do not distinguish between active and inactive transport or define it as total PA [54] or commuting [11]. A study by Foley et al. [20] could, however, associate time in active transport with spending more time on healthy behaviours. In summary, participation in active transport offers a good opportunity for older adults as health promoting behaviour.

Our results show sex differences in time allocation regarding home-based activities. The sex differences are in line with previous research [12, 23, 55], with women spending more time on household chores than men. Gauthier and Smeeding [24] reported the same findings for overall home-based activities in nine different countries, but, contrasting our results, saw a decrease with age in women devoting time to housework and an agerelated increase in men. We found no associations of home-based activities and health outcomes, which is supported by previous research, supporting the lack of associations of household chores and overweight [22] or health status [21]. Contrastingly, Adjei and Brand [12] found that older adults who spent more time doing home-based activities are more likely to report good health. These differences could stem from different measurements of home-based activities, including time-use diaries for one, 2 or 7 days with $24 \mathrm{~h}$ of data [12]. 
The study has a few limitations that need to be addressed. The questionnaire used in the OUTDOOR ACTIVE study was not initially designed for time use analyses, thus some domains of the SLOTH model were not fully assessed. Furthermore, we have not performed any type of reproducibility of the questionnaire. However, several components from validated questionnaires were used in our study [38-40]. Moreover, the assessment of housework and gardening might be biased, since it was not clarified which tasks account to these domains. It is, for example, unknown whether the participants included cooking to housework or only referred to cleaning. Moreover, the activity "riding a bike" was excluded from the leisure domain, since it is possible that participants included time spent on riding a bike for transport in their answer. This could lead to underestimated time in this domain. Since the participants had to estimate their weekly time spent in leisure and household activities, recall bias and reporting errors could be an issue. The use of a proper time use diary could reduce these risks. Additionally, they would deliver data for full 24-h days. However, the results of the present study are still a good indicator for the time allocation to active domains in older adults. The assessment of transport only included everyday destinations, leaving out travelling to work, social events, or other obligations, which could lead to an underestimation of time allocation. Another limitation of this study is the crosssectional design. Therefore, no statements regarding causation can be made and associations because of possible reverse causation (e.g. between PA and self-rated health, between occupation and self-rated health, or between active transport and limitations when walking more than $1 \mathrm{~km}$ ) cannot be determined. Thus, future research should look at time allocation and PA, and its effect on health outcomes in a longitudinal study.

One strength of this study is the representativeness of the sample for the population of Bremen-Hemelingen, when comparing social demographic factors. Furthermore, the PA data was assessed objectively using accelerometers, which is a reliable measurement for PA in older adults [6]. Furthermore, the SLOTH model is a well-known and fitting time budget model to analyse time allocation regarding PA [56].

This study provided insights in time allocation of older adults to active domains and PA, which are important information for developing PA programs and guidelines. Additionally, associations of time use and several health indicators were presented. These findings can help to develop new PA guidelines, which mostly incorporate overall PA in minutes and intensity but do not take the different life domains into consideration. If guidelines also include domains, specific PA promotion programs could be designed accordingly. Additionally, the knowledge of the associations between health indicators and PA in different domains can help practitioners in tackling health problems. For example, overweight and obesity prevention programs could incorporate the promotion of active transport, which might be easier for some participants to realise than starting and following an exercise programme.

\section{Conclusions}

The findings of this study have shown differences by age, sex, and occupational status in time allocation to active domains of daily living as well as in objectively measured PA in older adults. Furthermore, time use was associated with several health outcomes. Healthy ageing, and in this context also active ageing, is an important public health goal. This study provides information on how older adults structure their day, which active domain they devote most time to, and which health indicators are associated with active domains, which has important implications for the development of PA programs. It shows that PA is beneficial for healthy ageing and that active domains should be integrated in PA promotion and the development of PA guidelines. For example, active transport could be used for obesity prevention, and the increase of leisure activities for reducing limitations in ADL. However, further research and longitudinal studies are needed to understand the specific links between time allocation to active domains and health indicators to increase active living as a part of healthy ageing.

\section{Supplementary information}

Supplementary information accompanies this paper at https://doi.org/10. 1186/s12889-020-09708-z.

Additional file 1. Estimated number of visits per week to common destinations. To calculate time in active transport, we estimated the number of visits per week to the common destinations, that were used in the questionnaire.

\section{Abbreviations}

ADL: Activities of Daily Living; BMI: Body Mass Index; CPM: Counts per minute; MVPA: Moderate to vigorous physical activity; PA: Physical activity; SES: Socioeconomic status; SLOTH model: Sleep, Leisure activities,

Occupation, Transport, Home-based activities

\section{Acknowledgements \\ The authors would like to thank all participants of the OUTDOOR ACTIVE study.}

\section{Authors' contributions}

IS performed statistical analyses and drafted the manuscript. KB contributed to the conception and design of the study as well as statistical analyses. KB, BMA and FD critically revised and reviewed the manuscript. All authors read and approved the final manuscript.

\section{Funding}

The OUTDOOR ACTIVE study is funded by the German Federal Ministry of Education and Research (BMBF). The funder had no role in the design of the study, data collection, or analysis, interpretation of data and in writing the manuscript. Open Access funding enabled and organized by Projekt DEAL. 


\section{Availability of data and materials}

The datasets used and/or analysed during the current study are available from the corresponding author on reasonable request.

\section{Ethics approval and consent to participate}

The OUTDOOR ACTIVE study was approved by the ethics committee of the University of Bremen. All participants provided written informed consent.

\section{Consent for publication}

Not applicable.

\section{Competing interests}

The authors declare that they have no competing interests.

\section{Received: 1 July 2020 Accepted: 15 October 2020}

\section{Published online: 20 October 2020}

\section{References}

1. Peel NM, McClure RJ, Bartlett HP. Behavioral determinants of healthy aging. Am J Prev Med. 2005;28(3):298-304

2. World Health Organization. Global recommendations on physical activity for health. Geneva: World Health Organization; 2010.

3. Sun F, Norman IJ, While AE. Physical activity in older people: a systematic review. BMC Public Health. 2013;13:449.

4. Lear SA, Hu W, Rangarajan S, Gasevic D, Leong D, lqbal R, et al. The effect of physical activity on mortality and cardiovascular disease in 130000 people from 17 high-income, middle-income, and low-income countries: the PURE study. Lancet. 2017;390(10113):2643-54.

5. Krug S, Jordan S, Mensink G, Müters S, Finger J, Lampert T. Physical activity: results of the German health interview and examination survey for adults (DEGS1). Bundesgesundheitsbl. 2013;56(5-6):765-71.

6. Garatachea N, Torres-Luque G, González-Gallego J. Physical activity and energy expenditure measurements using accelerometers in older adults. Nutr Hosp. 2010;25(2):224-30

7. Hallal PC, Andersen LB, Bull FC, Guthold R, Haskell W, Ekelund U. Global physical activity levels: surveillance progress, pitfalls, and prospects. Lancet. 2012:380(9838):247-57.

8. Hills AP, Mokhtar N, Byrne NM. Assessment of physical activity and energy expenditure: an overview of objective measures. Front Nutr. 2014;1:5.

9. Dumuid D, Lewis LK, Olds TS, Maher C, Bondarenko C, Norton L. Relationships between older adults' use of time and cardio-respiratory fitness, obesity and cardio-metabolic risk: a compositional isotemporal substitution analysis. Maturitas. 2018;110:104-10.

10. Bauman A, Bittman M, Gershuny J. A short history of time use research; implications for public health. BMC Public Health. 2019;19(2):607.

11. Abu-Omar K, Rutten A. Relation of leisure time, occupational, domestic, and commuting physical activity to health indicators in Europe. Prev Med. 2008; 47(3):319-23.

12. Adjei NK, Brand T. Investigating the associations between productive housework activities, sleep hours and self-reported health among elderly men and women in western industrialised countries. BMC Public Health 2018;18(1):110.

13. Adjei NK, Brand T, Zeeb H. Gender inequality in self-reported health among the elderly in contemporary welfare countries: a cross-country analysis of time use activities, socioeconomic positions and family characteristics. PLoS One. 2017;12(9):e0184676.

14. White RL, Babic MJ, Parker PD, Lubans DR, Astell-Burt T, Lonsdale C. Domain-specific physical activity and mental health: a meta-analysis. Am J Prev Med. 2017:52(5):653-66.

15. Saint-Maurice PF, Coughlan D, Kelly SP, Keadle SK, Cook MB, Carlson SA, et al. Association of Leisure-Time Physical Activity across the adult life course with all-cause and cause-specific mortality. JAMA Netw Open. 2019; 2(3):e190355.

16. Kulmala J, Ngandu T, Pajala S, Lehtisalo J, Levälahti E, Antikainen R, et al. Leisure-time and occupational physical activity in early and late adulthood in relation to later life physical functioning. J Phys Act Health. 2016;13(10): 1079-87.

17. Hu G, Qiao Q, Silventoinen K, Eriksson JG, Jousilahti P, Lindstrom J, et al. Occupational, commuting, and leisure-time physical activity in relation to risk for type 2 diabetes in middle-aged Finnish men and women. Diabetologia. 2003;46(3):322-9.
18. Hu G, Sarti C, Jousilahti P, Silventoinen K, Barengo NC, Tuomilehto J. Leisure time, occupational, and commuting physical activity and the risk of stroke. Stroke. 2005;36(9):1994-9.

19. van der Heide I, van Rijn RM, Robroek SJW, Burdorf A, Proper KI. Is retirement good for your health? A systematic review of longitudinal studies. BMC Public Health. 2013;13:1180.

20. Foley L, Dumuid D, Atkin AJ, Olds T, Ogilvie D. Patterns of health behaviour associated with active travel: a compositional data analysis. Int J Behav Nutr Phys Act. 2018;15(1):26.

21. Wen $X$, Liang $Y$, Zhu J, Wu T. The effects of housework on the health of retired older adults: a preliminary investigation from the Tongji-Dongfeng cohort study, China. PLoS ONE. 2013;8(3):e57232.

22. Lawlor DA, Taylor M, Bedford C, Ebrahim S. Is housework good for health? Levels of physical activity and factors associated with activity in elderly women. Results from the British Women's heart and health study. J Epidemiol Community Health. 2002;56(6):473-8.

23. Sprod J, Olds T, Brown W, Burton N, van Uffelen J, Ferrar K, et al. Changes in use of time across retirement: a longitudinal study. Maturitas. 2017;100:70-6.

24. Gauthier AH, Smeeding TM. Time use at older ages:cross-National Differences. Res Aging. 2003;25(3):247-74.

25. Rhodes RE, Mark RS, Temmel CP. Adult sedentary behavior: a systematic review. Am J Prev Med. 2012;42(3):e3-e28.

26. Espinel PT, Chau JY, van der Ploeg HP, Merom D. Older adults' time in sedentary, light and moderate intensity activities and correlates: application of Australian time use survey. J Sci Med Sport. 2015;18(2):161-6.

27. Eibich P. Understanding the effect of retirement on health: mechanisms and heterogeneity. J Health Econ. 2015:43:1-12.

28. Celidoni M, Rebba V. Healthier lifestyles after retirement in Europe? Evidence from SHARE. Eur J Health Econ. 2017;18(7):805-30.

29. Forberger S, Bammann K, Bauer J, Boll S, Bolte G, Brand T, et al. How to Tackle Key Challenges in the Promotion of Physical Activity among Older Adults (65+): The AEQUIPA Network Approach. Int J Environ Res Public Health. 2017;14(4):379.

30. Bammann K, Drell C, Lübs LL, Stalling I. Cluster-randomised trial on participatory community-based outdoor physical activity promotion programs in adults aged 65-75 years in Germany: protocol of the OUTDOOR ACTIVE intervention trial. BMC Public Health. 2018;18(1):1197.

31. Rikli RE, Jones CJ. Senior fitness test manual. 2nd ed. Human Kinetics: Leeds; 2013. p. 186.

32. Troiano RP, McClain JJ, Brychta RJ, Chen KY. Evolution of accelerometer methods for physical activity research. Br J Sports Med. 2014;48(13):1019-23.

33. Skender S, Ose J, Chang-Claude J, Paskow M, Brühmann B, Siegel EM, et al. Accelerometry and physical activity questionnaires - a systematic review. BMC Public Health. 2016:16:515.

34. Kowalski K, Rhodes R, Naylor P-J, Tuokko H, MacDonald S. Direct and indirect measurement of physical activity in older adults: a systematic review of the literature. Int J Behav Nutr Phys Act. 2012;9:148.

35. Zhao LP, Kolonel LN. Efficiency loss from categorizing quantitative exposures into qualitative exposures in case-control studies. Am J Epidemiol. 1992;136(4):464-74.

36. Choi L, Liu Z, Matthews CE, Buchowski MS. Validation of accelerometer wear and nonwear time classification algorithm. Med Sci Sports Exerc. 2011;43(2): 357-64.

37. Cawley J. An economic framework for understanding physical activity and eating behaviors. Am J Prev Med. 2004:27(3 Suppl):117-25.

38. Saelens BE, Sallis JF, Black JB, Chen D. Neighborhood-based differences in physical activity: an environment scale evaluation. Am J Public Health. 2003; 93(9):1552-8.

39. Jenkinson C, Wright L, Coulter A. Criterion validity and reliability of the SF36 in a population sample. Qual Life Res. 1994;3(1):7-12.

40. Tarlov AR, Ware JE Jr, Greenfield S, Nelson EC, Perrin E, Zubkoff M. The medical outcomes study: an application of methods for monitoring the results of medical care. JAMA. 1989;262(7):925-30.

41. World Health Organization. Obesity: preventing and managing the global epidemic, Report of a WHO consultation. Geneva: World Health Organization; 2000. Report No: 0512-3054 (Print).

42. Helmert U, Bammann K, Voges W, Müller R. Müssen Arme früher sterben?: Soziale Ungleichheit und Gesundheit in Deutschland. Juventa Verlag GmbH: Weinheim; 2000. p. 320.

43. Sperlich S, Beller J, Epping J, Tetzlaff J, Geyer S. Trends in self-rated health among the elderly population in Germany from 1995 to 2015 - the 
influence of temporal change in leisure time physical activity. BMC Public Health. 2020;20(1):113.

44. Abu-Omar K, Rütten A, Robine JM. Self-rated health and physical activity in the European Union. Soz Praventivmed. 2004:49(4):235-42.

45. Riebe D, Blissmer BJ, Greaney ML, Garber CE, Lees FD, Clark PG. The relationship between obesity, physical activity, and physical function in older adults. J Aging Health. 2009;21(8):1159-78.

46. Yorston LC, Kolt GS, Rosenkranz RR. Physical activity and physical function in older adults: the 45 and up study. J Am Geriatr Sco. 2012;60(4):719-25.

47. Edholm P, Nilsson A, Kadi F. Physical function in older adults: impacts of past and present physical activity behaviors. Scand J Med Sci Sports. 2019; 29(3):415-21.

48. Fairclough S, Noonan R, Rowlands A, van Hees V, Knowles Z, Boddy L. Wear compliance and activity in children wearing wrist and hip-mounted accelerometers. Med Sci Sports Exerc. 2015:48:245-53.

49. Jiménez-Jiménez FJ, Calleja M, Alonso-Navarro H, Rubio L, Navacerrada F, Pilo-de-la-Fuente $B$, et al. Influence of age and gender in motor performance in healthy subjects. J Neurol Sci. 2011;302(1-2):72-80.

50. Spinney JE, Millward H. Active living among older Canadians: a time-use perspective over 3 decades. J Aging Phys Act. 2014;22(1):103-13.

51. Krantz-Kent R, Stewart J. How do older Americans spend their time? Monthly Labor Review. 2007;130(5):8-26.

52. Kaleta D, Makowiec-Dabrowska T, Dziankowska-Zaborszczyk E, Jegier A. Physical activity and self-perceived health status. Int J Occup Med Environ Health. 2006;19(1):61-9.

53. Holstila A, Mänty M, Rahkonen O, Lahelma E, Lahti J. Changes in leisuretime physical activity and physical and mental health functioning: a followup study. Scand J Med Sci Sports. 2017;27(12):1785-92.

54. Flood SM, Moen P. Healthy time use in the encore years: do work, resources, relations, and gender matter? J Health Soc Behav. 2015;56(1):7497.

55. Sprod JA, Olds TS, Burton NW, Brown WJ, van Uffelen JG, Ferrar KE, et al. Patterns and correlates of time use and energy expenditure in older Australian workers: a descriptive study. Maturitas. 2016;90:64-71.

56. Pratt M, Macera CA, Sallis JF, O'Donnell M, Frank LD. Economic interventions to promote physical activity: application of the SLOTH model. Am J Prev Med. 2004;27(3 Suppl):136-45.

\section{Publisher's Note}

Springer Nature remains neutral with regard to jurisdictional claims in published maps and institutional affiliations.

Ready to submit your research? Choose BMC and benefit from:

- fast, convenient online submission

- thorough peer review by experienced researchers in your field

- rapid publication on acceptance

- support for research data, including large and complex data types

- gold Open Access which fosters wider collaboration and increased citations

- maximum visibility for your research: over $100 \mathrm{M}$ website views per year

At $\mathrm{BMC}$, research is always in progress.

Learn more biomedcentral.com/submissions 